W S R C - T R -92-078

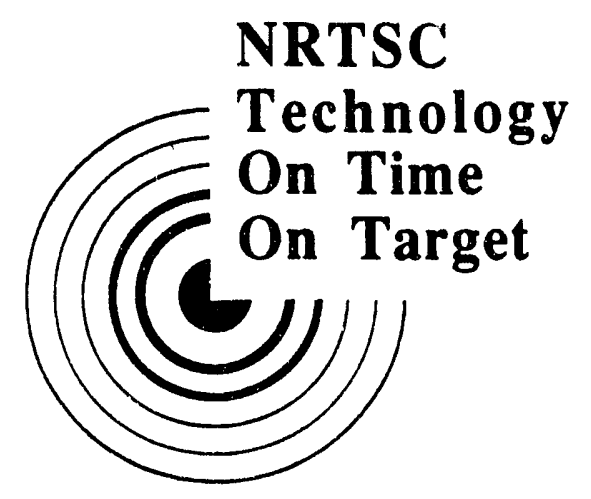

WSRC-TR--92-078

DE93 005167

KEY WORDS:

SHIELD

VALIDATION

CERTIFICATION

RETENTION PERIOD:

LIFETIME

\title{
SHIELD CERTIFICATION PACKAGE (U)
}

B y

Christa Boman

ISSUED: February 1992

SRL SAVANNAH RIVER LABORATORY, AIKEN, SC 29808 Westinghouse Savannah River Company

Prepared for the U. S. Department of Energy under Contract DE.AC09.8\%SR 18035 
DOCUMENT: WSRC-TR-92-078

TITLE:

SHIELD CERTIFICATION PACKAGE (U).

TASK: CERTIFICATION PLAN FOR SHIELD (91-013-1).

APPROVALS

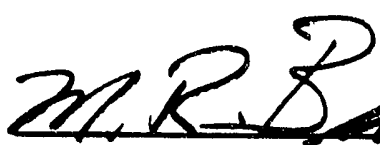

M. R. BUCKNER, MANAGER

DATE2-19-92

SCIENTIFIC COMPUTATIONS SECTION

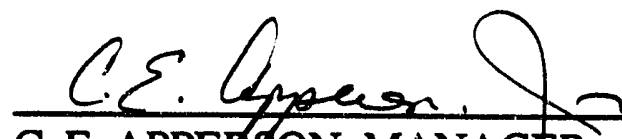

C. E. APPERSON, MANAGER

DATE $2-17-92$ REACTOR PHYSICS GROUP

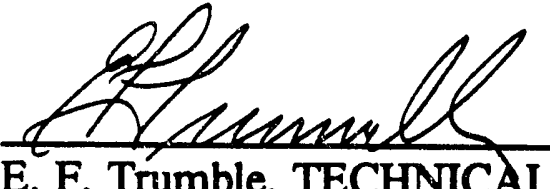

E. F. Trumble, TECHNICAL REVIEWER

DATE $\underline{2-10-92}$ 


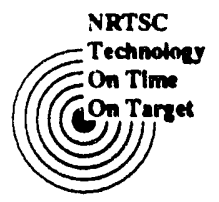

SHIELD Certification Package

WSRC-TR-92-078

February 1992

Page 1 of 8

\section{INTRODUCTION AND SUMMARY}

In response to a Department of Energy (DOE) request to verify that the tools used at the Savannah River Site to develop technical specifications for operations are valid, Westinghouse Savannah River Company committed to certify all computer codes used in critical calculations at the site (Ref. 1). The certification procedures were prepared and reported in Refs. 2 \& 3.

Certification as applied to existing computer codes includes the verification and validation process, placing the code in configuration control, establishing user qualification standards and training requirements. All software intended for use in critical calculations must be certified. This report is intended to fulfill the requirements for the certification of the SHIELD, SHLDED, GEDIT, GENPRT, FIPROD, FPCALC, and PROCES modules of the SHIELD system built February, 1592, by W. S. Parks. These modules are used for burnup, cooling, separate, and edit calculations. The report follows the requirements of QAP IV-2 of the NRTSC QA Procedures.

This work was performed under NRTSC QA task \#91-013-1, Certification Plan for SHIELD, and is documented in Ref. 4. This certification package only satisfies the certification requirements for the SHIELD, SHLDED, GEDIT, GENPRT, FIPROD, FPCALC, and PROCES modules of the SHIELD system. It is not certification of the complete SHIELD system. Complete certification will follow at a later date. 


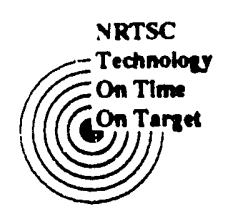

SHIELD Certification Package

\section{DISCUSSION}

\section{Application}

The modules being certified are SHIELD, SHLDED, GEDIT, GENPRT, FIPROD, FPCALC, and PROCES. These are a set of computational modules that provide an accurate calculation of:

(1) Reactor irradiation or burnup;

(2) Isotopic inventory from spontaneous decay;

(3) Isotopic inventory changes from fuel cycle processes; and

(4) Editing.

The most fundamental problem solved by the SHIELD system is the time dependent isotopic inventory of a nuclear material as it flows within and between the fuel cycle processes. Historically, computer codes (Refs. 5-8) specific to one part of the fuel cycle have been utilized for this purpose. Most of these codes have a limited range of applicability because of the extensive nuclear data base required, (Ref. 9) and the large amount of information that must be communicated from one fuel cycle process to the next. The SHIELD system brings together computational modules applicable to all parts of the fuel cycle, an extensive nuclear data base, and a communications methodology that permits information flow from calculation to calculation in different parts of the fuel cycle.

The code is used extensively by the Criticality Methods and Analysis, and Reactor Assistance tasks of the Reactor Physics Group, the Core Neutronics Group of the NPR division, and by Reactor Engineering. SHIELD is executed on the IBM 3090 under the JOSHUA operating system (Ref. 10).

The concept for the SHIELD system arose from shielding design and assessment needs of the Converter Fuels Program (CFP), Away From the Reactor Storage (AFR), and Defense Waste Processing Facility (DWPF) programs at the Savannah River Plant. Design studies for the SHIELD system were begun in 1976 (Ref. 11), and the first computational modules implemented in 1977. The extensive nuclear data base was 
WSR C.T R-92-078

SHIELD Certification Package

February 1992

Page 3 of 8

implemented between 1976 and 1978 with additions in 1980-1981, and 1987 (Ref. 12). The final computational modules were completed in 1981 .

\section{Input}

User data is stored on input records created via the JOSHUA system (Ref. 10). A complete description of all input records is given in Ref. 12, which also describes which records are required for different calculation types.

\section{Output}

The SHIELD code generates an ASCII file (commonly referred to as an outlisting) and numerous JOSHUA records as output. The outlisting contains all results of the calculations to a detail consistent with that requested by the user in the input. This may include an echo of the input data, isotopic inventory, radiation source spectra, and dose rates.

\section{Solution Method}

The solution methods of the FIPROD, FPCALC and PROCESS modules are described here.

The decay and/or buildup of radioactive nuclides under conditions of spontaneous decay is solved by modules FIPROD and FPCALC. The FIPROD module calls the FPCALC module to perform the actual production-depletion calculation using either the linearized chain or matrix exponential mathematical algorithms. The time dependent isotopic composition is solved for using a first order differential equation for burnup. The FPCALC module being certified here assumes space independent fluxes and cross sections, or that any space dependence of fluxes and cross sections has been averaged into the input information. FIPROD is also capable of performing a cooling calculation which computes the isotopic inventory of radionuclides under zero-flux conditions. 
WSR C-T R-92-078

SHIELD Certification Package

February 1992

Page 4 of 8

Two mathematical algorithms are available in the FIPROD module for the burnup or cooling calculations. The LINCHAIN option approximates the coupling matrix between isotopes to a vector representation and solves the vector problem by an explicit solution. This mathematical algorithm is similar to that used in the CINDER code (Ref. 5). The MATEXP option uses the matrix exponential approximation to the full matrix solution. This mathematical algorithm is the same used in the ORIGEN code (Ref. 6).

The PROCES module of the SHIELD system simulates the mechanical and chemical fuel cycle processes. The quantity conserved in the normal fuel cycle calculation is the total mass of each isotope that enters and leaves a process vessel. More detailed solution method descriptions of FIPROD, FPCALC, and PROCES can be found in Ref. 12, The SHIELD System User's Manual.

\section{Accuracy and Limitations}

SHIELD is currently limited to operation under the JOSHUA enviroument on the IBM 3090 computer system. The accuracy of SHIELD calculations is discussed in several validation and verification reports (Refs. 12 \&14).

\section{Code Source Listing Locations}

The source code for the SHIELD system modules currently being certified is stored under the Scientific Code Management System, which protects it from unauthorized changes, and ensures strict quality assurance standards are adhered to. The source listing for the IBM version of SHIELD is located on the VAX cluster, in the SCMS libraries SRLUSER3:[SCMS.SOURCE.SHIELD].

\section{Program Execution}

Instructions for executing SHIELD on the IBM under J80 version of JOSHUA, can be found in Ref. 15. A set of test problems has been developed which span the range of applications of the SHIELD modules being certified. The input and output from these problems are detailed 


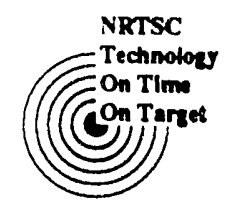

SHIELD Certification Package

WSR C-TR-92-078

February 1992

Page 5 of 8

in Ref. 16. The test problems can be found on the IBM in the data set USCS.SCMS.TEST.

\section{Access Control and Security}

The SHIELD code may be executed on the unclassified computing system at SRS. Changes to the SHIELD coding can be performed only by the code proprietor, and are implemented by the SCMS custodian only after satisfactory execution of the test problem set (Ref. 16).

Shell scripts and banners or page headings have been added to the SHIELD code. The banners are printed every time a new module is entered, and identify the version of the code and the date of compilation. The shell scripts are maintained by the SCMS custodian in accordance with the requirements of Ref. 17.

Technically knowledgeable personnel have been assigned to serve as code proprietor and backup proprietor for the SHIELD code. These proprietors are members of the user community who are experienced users of the code. The backup proprietor has been identified to ensure continuity of code expertise.

A proprietor's code notebook (Ref. 4) is being maintained in which an ongoing history of code development, alterations, validation, and error corrections are recorded. This notebook will be continuously maintained by the code proprietor.

\section{User Qualifications}

Requirements for qualification and training as apprentice and cognizant users of the SHIELD code are identified in Ref. 15. Training must be supervised by a cognizant user at a qualification level at or above the level the trainee wishes to obtain.

\section{Manual and Other Documentation}

A users manual has been written for SHIELD which details code theory, input and output (Ref. 12). The manual is controlled by hard copy 
WSR C-TR-92-078

SHIELD Certification Package

February 1992

Page 6 of 8

receipt, so that further changes and updates will be received by all users.

A controlled tracking system is in place to inform all cognizant users of coding and system changes in the SHIELD code. All memoranda issued via this system are numbered and approved by management. The cognizant users list is maintained by the code proprietor.

\section{Technical Review}

A technical review of this document has been performed in accordance with QAP II-14 of the NRTSC QA Manual. The review sheets will be maintained as part of the official task records. 


\section{REFERENCES}

1. Letter, Technical Specification Parameter Justification, P.W. Dickson to R.E. Tiller, August 11, 1989.

2. H. Toffer, R.D. Crowe, K.N. Schwinkendorf, and R.E. Pevey, Certification Plan for Reactor Analysis Computer Codes (U), WSRC-TR-90-26, January 1990.

3. H. Toffer, R.D. Crowe, K.N. Schwinkendorf, and R.E. Pevey, Verification and Validation Plan for Reactor Analysis Computer Codes (U), WSRC-RP89-1249, November 1989.

4. A. W. Tipton, SHIELD Proprietor's Notebook, WSRC-NB-90-301, September 1990.

5. T. R. England, et al., Fission Product Data for Thermal Reactors, Part 1: A Data Set for EPRI-CINDER Using ENDF/B-IV, and Part 2: Users Manual For EPRI-CINDER Code and Data. Electric Power Research Institute, EPRINP-356, 1970.

6. M. J. Bell, ORIGEN: The ORNL Isotope and Depletion Code, Oak Ridge National Laboratory, ORNL-4628, 1973.

7. W. W. Engle, Jr., A Users Manual For ANISN, Oak Ridge Gaseous Diffusion Plant, K-1693, 1967.

8. K. D. Lathrop and F. W. Brinkley, TWOTRAN-II: An Interfaced, Exportable Version of the TWOTRAN Code For Two-Dimensional Transport, Los Alamos Scientific Laboratory, LA-4848-MS, 1973.

9. D. E. Bartine, et al., Production and Testing of the DNA Few-Group Coupled Neutron-Gamma Cross Section Library, Oak Ridge National Laboratory, ORNL-TM-4840, 1977.

10. W.H. Reed, H.C. Honeck, J.T. McCort, B.W. Westmoreland, The JOSHUA User's Manual, DPSPM-GEN-36, September 14, 1987. 


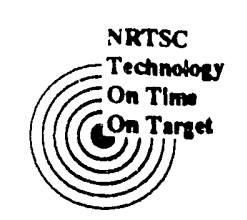

SHIELD Certification Package

WSR C-TR-92-078

February 1992

Page 8 of 8

11. D. R. Finch and R. J. Pryor, Program For The Development of a Shielding Computation System for All Phases of Light Water Reactor Fuel Reprocessing, DPST-LWR-76-105, 1976.

12. D. R. Finch, The SHIELD System User's Manual, DPSTM-87-700-2, October 1988.

13. R. L. Frost and S. H. Finfrock, A New User's Manual for GLASS (U), WSRC-TR-91-143, January 1992.

14. C. Boman, SHIELD Verification and Validation Report, WSRC-TR-92076, February 1992.

15. C. Boman, SHIELD User Notification \#92-01, SCS-RPG-920034, February 1992.

16. C. Boman, A Sttritard Set of Test Problems for SHIELD, WSRC-TR92-075, February 1992.

17. J.C. Jensen, SCMS Entry Procedure, TP-90-019, November 15, 1990. 

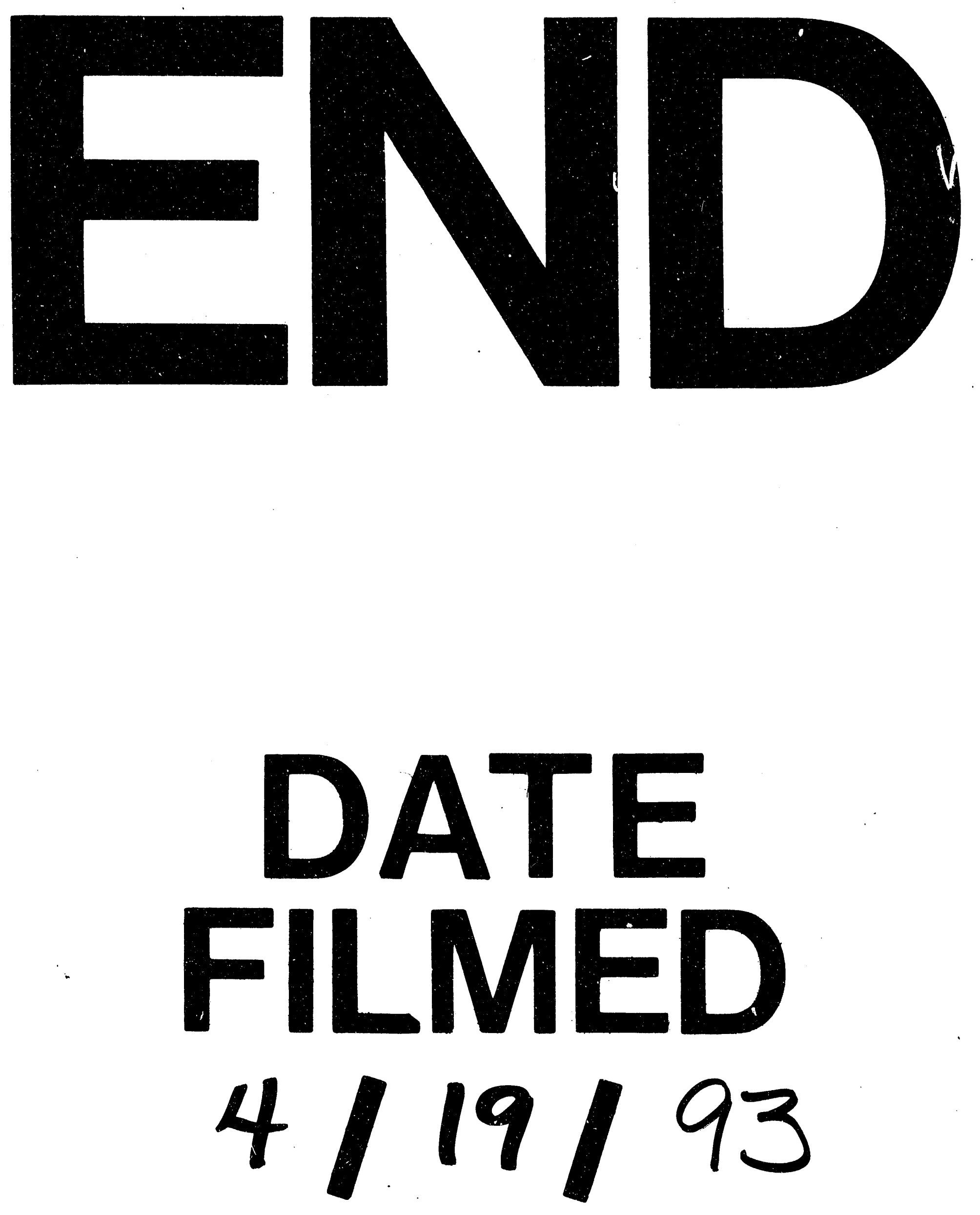
